\title{
UPAYA MENINGKATKAN SOSIAL EMOSIONAL ANAK MELALUI PERMAINAN BAKIAK DI KELOMPOK B KB NURUL YAQIN WRINGIN ANOM ASEMBAGUS SITUBONDO
}

\author{
Lailatul Islamiyah', Suyanti ${ }^{2}$, \\ ${ }^{1}$ Pendidikan Islam Anak Usia Dini,Tarbiyah, Universitas Ibrahimy Situbondo \\ ${ }^{2}$ Psikologi, Sosial dan Humaniora, Universitas Ibrahimy Situbondo \\ E-mail: islamiyalailatul2@gmail.com
}

\begin{abstract}
ABSTRAK: Perkembangan sosial emosional anak penting dikembangkan karena untuk rasa percaya diri, kemandirian, dan inisiatif anak. Perkembangan sosial emosional anak dapat dikembangkan melalui permainan bakiak. Adapun tujuan pada penelitian ini adalah mengetahui pelaksanaan dan hasil pada kegiatan permainan bakiak dalam upaya meningkatkan sosial emosional anak. Jenis penelitian yang digunakan adalah Penelitian Tindakan Kelas (PTK) pada siswa kelompok B di KB Nurul Yaqin Wringin Anom Asembagus Situbondo. Penelitian dilakukan secara bersiklus, yaitu setiap siklus terdiri dari perencanaan, tindakan, observasi, dan refleksi dengan tujuan untuk meningkatkan kualitas pembelajaran di kelas. Berdasarkan hasil penelitian yaitu pelaksanaan permainan bakiak untuk meningkatkan perkembangan sosial emosional anak di KB Nurul Yaqin meliputi; guru membagi kelompok, setiap kelompok terdiri dari 2-3 anak sesuai dengan kapasitas sandal bakiak. Pada hasil pelaksanaan kegiatan menunjukkan adanya peningkatan pada aspek perkembangan sosial emosional anak melalui permainan bakiak, yakni Pra siklus, nilai prosentase mencapai $37.5 \%$. Adapun rata-rata pencapaian indikator anak adalah 4.5. Setelah tindakan Siklus I, nilai prosentase mencapai $75 \%$ dengan pencapaian indikator adalah 6 . Pada Siklus II nilai prosentase mencapai $87.5 \%$ dengan nilai pencapaian indikator anak adalah 7.5 .
\end{abstract}

Kata Kunci: Sosial Emosional; Permainan Bakiak

\begin{abstract}
The emotional social development of children is important to develop due to their self-confidence, independence and initiative. Children's emotional social development can be developed through clogs. The purpose of this study is to determine the implementation and results of clogs in an effort to improve children's social emotional. The type of research used is Classroom Action Research (CAR) on group B students at KB Nurul Yaqin Wringin Anom Asembagus Situbondo. The study was conducted in a cycle, which is each cycle consisting of planning, action, observation, and reflection with the aim to improve the quality of learning in the classroom. Based on the results of the study, namely the implementation of clogs to improve children's emotional social development at KB Nurul Yaqin includes; The teacher divides the groups, each group consists of 2-3 children according to the capacity of clogs. On the results of the implementation of the activity showed an increase in aspects of social emotional development of children through clogs, namely Pre-cycle, the percentage value reached $37.5 \%$. The average achievement of child indicators is 4.5 . After the Cycle I action, the percentage value reaches $75 \%$ with the achievement of the indicator being 6 . In Cycle II the percentage value reaches $87.5 \%$ with the achievement value of the child indicator being 7.5 .
\end{abstract}

Keywords: Emotional Social; Clogs game 


\section{PENDAHULUAN}

Awal kehidupan pada anak usia dini merupakan masa yang paling tepat dalam memberikan dorongan atau upaya pengembangan agar dapat berkembang secara optimal. Perkembangan pada anak di masa depan akan sangat ditentukan oleh berbagai stimulus bermakna yang diperoleh saat usia dini. Pendidikan anak usia dini (paud) merupakan pendidikan yang sangat fundamental.

Menurut UU no. 20 tahun 2003 tentang system pendidikan nasional bab I pasal 1 butir 14 menyatakan bahwa PAUD adalah pengupayaan dalam pembinaan kepada anak usia o tahun sampai dengan usia 6 tahun untuk memberikan rangsangan pendidikan sehingga membantu pertumbuhan dan perkembangan jasmani dan rohani agar anak memiliki kesiapan belajar dalam memasuki pendidikan lebih lanjut. Undang-undang ini mengamanatkan bahwa pendidikan harus dipersiapkan secara terencana dan bersifat holistik sebagai dasar anak memasuki pendidikan lebih lanjut.

Secara garis besar perkembangan anak dapat dilihat melalui dari beberapa aspek. Yaitu perkembangan agama dan moral, perkembangan kognitif, perkembangan bahasa, perkembangan fisik motorik, perkembangan social emosional dan perkembangan seni. Sehingga dalam penelitian ini lebih mengarah pada aspek perkembangan sosial emosional anak.

Perkembangan sosial merupakan sebuah hubungan interaksi antara anak dengan orang lain, mulai dari orang tua, saudara, teman bermain, hingga masyarakat luas. Sementara perkembangan emosional adalah luapan perasaan ketika anak berinteraksi dengan orang lain. Dengan demikian, perkembangan sosial emosional adalah kepekaan anak untuk memahami perasaan orang lain ketika berinteraksi dalam kehidupan sehari-hari (Suyadi, 2010: 108-109).

Berdasarkan hasil observasi dengan jumlah 8 anak yang dilakukan penelitian, pada kenyataan yang terjadi sebagian anak kelompok B KB Nurul Yaqin dalam perkembangan sasial emosional anak khususnya dalam hal berbagi dan bekerja sama yang masih belum berkembang dengan baik. Hal tersebut terlihat pada saat guru mengajak peserta didik melakukan kegiatan kelompok, sesuai hasil pengamatan anak masih banyak yang belum mau berbagi dan bekerja sama dengan temannya.

Secara terperinci permasalahan yang ada pada anak sebagai berikut: 1) Anak kesulitan mengendalikan emosinya karena terbukti ketika diajak bermain secara berkelompok, Karena anak ingin bermain sendiri. Hal ini disebabkan oleh kurangnya sosialisasi anak terhadap teman sebaya dan lingkungannya. 2) Kurangnya kesabaran dalam menunggu giliran pada saat permainan berlangsung. Karena di lingkungan keluarganya anak selalu dinomor satukan atau dikedepankan. 3) Kurangnya anak bersosialisasi antara satu sama lain karena anak lebih asyik bermain sendiri dengan mainan yang mereka sukai yang meraka bawa. 4) Kurangnya pemahaman anak terhadap permainan tradisional, karena anak suka bermain game online. Orang tuanya juga kurang memberikan pengenalan tentang permainan tradisional. Sehingga anak lebih suka menyendiri.

Sebagai guru Kelompok Bermain (KB) menyadari bahwa menjadi guru harus mempunyai inovasi yang bisa menarik minat anak yang bersifat baru dan menarik. Dan guru juga harus banyak mencari inovasi-inovasi baru yang mampu menarik minat anak. Oleh karena itu, peneliti melakukan penelitianyaitu upaya meningkatkan sosial emosi anak melalui permainan bakiak pada kelompok B di KB Nurul Yaqin Wringin Anom.

\section{METODE PENELITIAN}

Jenis penelitian ini yang digunakan adalah penelitian tindakan kelas (classroom action research). Penelitian ini merupakan penelitian yang menekankan pada suatu strategi memecahkan dari suatu masalah 
yang memanfaatkan tindakan praktis nyata dalam mendeteksi dan pemecahan masalah. Penelitian tindakan kelas yang nantinya akan digunakan berupa siklus-siklus yang terdiri dari empat komponen meliputi perencanaan (planning), tindakan (acting), pengamatan (observing), dan refleksi (reflecting) sebagaimana konsep model penelitian yang dikembangkan oleh Jhon Elliot (Muliawar, 2010: 25).

Subyek penelitian ini adalah kelompok B di KB Nurul Yaqin Wringin Anom. Dimana anak kelas $B$ berjumlah 8 anak terdiri dari 3 anak laki-laki dan 5 anak perempuan yang rata-rata semuanya berusia 3-4 tahun. Lokasi penelitian di Jl. Banongan Utara Rt 02 Rw o6 Wringin Anom Asembagus - Situbondo 68373. Waktu pelaksanaan penelitian dimulai sejak bulan januari sampai dengan selesai.

\section{PEMBAHASAN}

Pelaksanaan Permainan Bakiak Dalam Upaya Meningkatkan Sosial Emosional Anak

Pelaksanaan permainan bakiak digunakan sebagai metode pembelajaran untuk meningkatkan sosial emosional anak. Sosial emosional anak merupakan adanya perubahan dari perilaku disertai perasaan tertentu pada anak usia dini saat melakukan sosialisasi dengan orang lain. Permainan bakiak yang dilaksanakan di KB Nurul Yaqin dilakukan oleh guru bersama anak secara berkelompok. Guru berperan sebagai model atau contoh, sedangkan anak-anak menyimak, merespon, dan meniru gerakan yang dicontohkan oleh guru. Setelah guru mencontohkan, anak bermain bakiak secara berkelompok dan guru mengawasi anak pada saat bermain. Sehingga guru bisa mengetahui perkembangan sosial emosional anak khususnya dalam hal bekerja sama dan bersabar dalam menunggu giliran.

Adapun cara bermain bakiak yaitu terlebih dahulu guru membagi kelompok, setiap kelompok terdiri dari 2-3 anak sesuai dengan kapasitas sandal bakiaknya. Setiap permain dalam kelompok memakai bakiak bersamaan di garis start. Setelah aba-aba, setiap kelompok yang telah memakai bakiak saling berlomba-lomba tiba di garis yang telah ditentukan dan kembali lagi ke garis start. Agar dapat berjalan cepat dan tidak terjatuh, diperlukan kekompakan pemain dalam satu kelompok.

Sebelum memulai permainan, guru menjelaskan peraturan bermain. Diantaranya yaitu agar anak bekerja sama, dapat menunggu giliran dan mampu bersosialisasi, baik didalam kelompok sendiri maupun kelompok yang lain. Peraturan tersebut diharapkan dapat meningkatkan perkembangan sosial emosional anak melalui permainan bakiak.

\section{Hasil Pelaksanaan Kegiatan Permainan Bakiak}

Pada permainan bakiak menunjukkan adanya peningkatan pada aspek sosial emosional anak. Dimana anak mampu berinteraksi dan bekerja sama dengan orang lain, mampu menunggu giliran dan bersosialisasi dengan orang lain. Berdasarkan penelitian observasi telah ditemukan perbandingan pada tingkat perkembangan sosial emosional anak. Hal ini ditunjukkan pada hasil penelitian Pra siklus, siklus I dan siklus II sebagaimana data pada tabel dibawah ini:

Tabel 1. Hasil Nilai Perkembangan Sosial Emosional Melalui Permainan Bakiak

\begin{tabular}{|r|l|l|l|l|}
\hline No & $\begin{array}{l}\text { Pencapaia } \\
\text { n }\end{array}$ & $\begin{array}{l}\text { Pra } \\
\text { siklu } \\
\text { s }\end{array}$ & $\begin{array}{l}\text { Siklu } \\
\text { s I }\end{array}$ & $\begin{array}{l}\text { Siklus } \\
\text { II }\end{array}$ \\
\hline $\mathbf{1}$ & Rata - rata & $4 \cdot 5$ & 6 & $7 \cdot 5$ \\
\hline 2 & $\begin{array}{l}\text { Pencapaian } \\
\text { Klasikal }\end{array}$ & $37 \cdot 5 \%$ & $75 \%$ & $87 \cdot 5 \%$ \\
\hline
\end{tabular}




\begin{tabular}{|c|c|c|c|c|c|c|}
\hline \multirow[b]{2}{*}{$\begin{array}{l}\text { Kate } \\
\text { gori } \\
\text { nilai }\end{array}$} & \multicolumn{3}{|c|}{ Jumlah anak } & \multicolumn{3}{|c|}{ Prosentase } \\
\hline & $\begin{array}{l}\text { Pra } \\
\text { Sikl } \\
\text { us }\end{array}$ & $\begin{array}{l}\text { Sikl } \\
\text { us I }\end{array}$ & $\begin{array}{l}\text { Sikl } \\
\text { us } \\
\text { II }\end{array}$ & $\begin{array}{l}\text { Pra } \\
\text { Sikl } \\
\text { us }\end{array}$ & $\begin{array}{l}\text { Sikl } \\
\text { us I }\end{array}$ & $\begin{array}{l}\text { Sikl } \\
\text { us } \\
\text { II }\end{array}$ \\
\hline $\begin{array}{l}\text { Berke } \\
\text { mban } \\
\mathrm{g} \\
\text { sangat } \\
\text { baik }\end{array}$ & - & 5 & 7 & - & $\begin{array}{l}62.5 \\
\%\end{array}$ & $\begin{array}{l}8.75 \\
\%\end{array}$ \\
\hline $\begin{array}{l}\text { Berke } \\
\text { mban } \\
\mathrm{g} \\
\text { sesuai } \\
\text { harap } \\
\text { an }\end{array}$ & 3 & 2 & 1 & $\begin{array}{l}2.25 \\
\%\end{array}$ & $25 \%$ & $\begin{array}{l}1.25 \\
\%\end{array}$ \\
\hline $\begin{array}{l}\text { Mulai } \\
\text { berke } \\
\text { mban } \\
\mathrm{g}\end{array}$ & 4 & 1 & - & $50 \%$ & $\begin{array}{l}12.5 \\
\%\end{array}$ & - \\
\hline $\begin{array}{l}\text { Belum } \\
\text { berke } \\
\text { mban } \\
\mathrm{g}\end{array}$ & 1 & - & - & $\begin{array}{l}12.5 \\
\%\end{array}$ & - & - \\
\hline
\end{tabular}

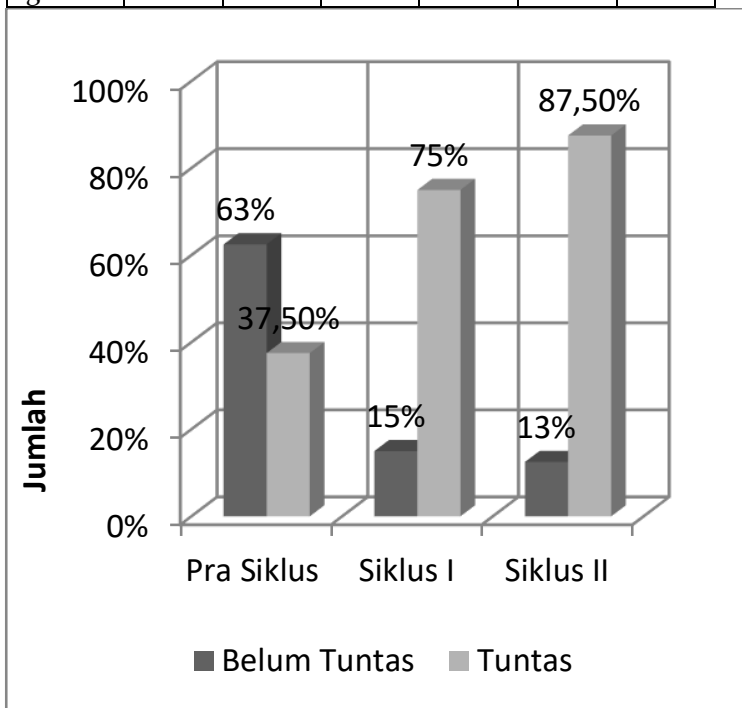

Grafik 1. Nilai Ketuntasan Pra Siklus, Siklus I, Dan Siklus II

Berdasarkan tabel dan grafik diatas, adapun nilai rata - rata pencapaian Indikator dan prosentase anak pada pra siklus, yaitu : 4.5 sedangkan untuk prosentase anak mencapai $37.5 \%$. Setelah diadakan tindakan kelas, Nilai rata - rata anak pada siklus I yaitu : 6 sedangkan untuk prosentase anak pada siklus I adalah $75 \%$, selanjutnya diadakan tindakan siklus II, hasil yang didapat anak nilai rata - rata mencapai 7.5 , sedangkan prosentase pada siklus II mencapai $87.5 \%$ dan sudah mencapai standar ketuntasan belajar.
Tabel 1.2 Rekapitulasi Perkembangan Sosial Emosional Anak

Berdasarkan rekapitulasi perkembangan sosial emosional anak melalui permainan bakiak di kelompok B KB Nurul Yaqin Wringin Anom Asembagus Situbondo, adapun anak yang mencapai BSB dan BSH di anggap tuntas. Jumlah anak yang tuntas pada pra siklus hanya 3 anak dengan jumlah prosentase nilai $37.5 \%$. Selanjutnya pada pelaksanaan tindakan kelas (siklus I), anak yang mencapai BSB dan BSH meningkat menjadi 7 anak dengan prosentase $75 \%$. Karena tidak mencapai standar kriteria ketuntasan minimal (80\%), maka diadakan tindakan kelas selanjutnya (siklus II), ternyata lebih meningkat dari sebelumnya, yaitu mencapai 8 anak dengan prosentase nilai $87,5 \%$. Pada tindakan siklus II dianggap berhasil karena telah melebihi kriteria ketuntasan minimal.

\section{KESIMPULAN}

Pelaksanaan permainan bakiak untuk meningkatkan perkembangan sosial emosional anak di KB Nurul Yaqin. Adapun cara bermain bakiak yaitu terlebih dahulu para pendidik membentuk kelompok yang terdiri dari 2-3 anak sesuai dengan kapasitas sandal bakiaknya. Para peserta didik yang menjadi pemain dalam kelompok memakai bakiak bersamaan di garis start. Ketika abaaba mulai, setiap kelompok yang telah memakai bakiak berlomba kecepatan untuk tiba di garis yang telah ditentukan dan kembali lagi ke garis start. Diperlukan adanya kekompakan para pemain dalam satu kelompok supaya berjalan dengan cepat dan tidak terjatuh,.

Hasil penelitian menunjukkan adanya peningkatan pada aspek perkembangan sosial emosional anak melalui permainan bakiak, yakni pada pra siklus, nilai prosentase anak mencapai $37.5 \%$. adapun rata - rata pencapaian Indikator anak adalah : 4.5. setelah dilakukan tindakan pada siklus I nilai prosentase mencapai $75 \%$ anak yang 
mencapai target Ketuntasan Belajar (KB), sedangkan rata - rata pencapaian Indikator yang dicapai anak adalah : 6. Adapun hasil dari tindakan pada siklus II perkembangan sosial emosional anak mengalami peningkatan, yakni tercatat bahwa nilai prosentase $87.5 \%$ dari jumlah keseluruhan anak, rata-rata pencapaian Indikator anak adalah : 7.5. siklus tidak dilanjutkan karena telah mencapai target ketuntasan klasikal yang ditetapkan.

\section{DAFTAR PUSTAKA}

Hariyanto. 2013. Pengantar Edutainment Pendidikan Anak Usia Dini. Jember:Perum Surya Mileniel.

Sujiona. 2009. Konsep Dasar Pendidikan Anak Usia Dini.Jakarta:PT Indeks.

Permendikbud. 2015. Kurikulum 2013 Pendidikan Anak Usia Dini.Jakarta:Kementrian Pendidikan Dan Kebudayaan

Suyadi. 2010. Psikologi Belajar Anak Usia Dini.Yogyakarta:Bintang Pedagogia.

Susanto,Ahmad. 2014. Perkembangan Anak Usia Dini Dalam Berbagai Aspek.Jakarta:Kencana Prenada Media Group.

Ardy Wiyani,Novan. 2014. Psikologi Perkembangan Anak Usia Dini.Yogyakarta:Gava Media.

Fudyartanta,Ki. 2012. Psikologi Perkembangan.Yogyakarta:Pustaka Belajar,

Mulyasa. 2012. Manajemen PAUD.Bandung:Rosdakarya

https://id.m.wikipedia.org/wiki/bakiak.Seja rah Dan Pengertian Bakiak,2019

Dani,Vardiansyah. 2008. Filsafat Ilmu Komunikasi.Jakarta:indeks.

Silalahi,Ulber. 2010. Metode Tindakan Kelas.Bandung:PT Refika Aditama.

Sanjaya,Wina. 2009. Penelitian Tindakan Kelas.Jakarta:Kencana Perdana.

Ungguh Muliawar, 2010. Jasa.Penelitian Tindakan Kelas.Yogyakarta:Gava Media.
Suprayogo,Imam. 2000. Metodologi Penelitian Sosial Agama.Bandung:Remaja Rosdakarya.

Tri Rahayu,Lin. 2002. Observasi Dan Wawancara.Malang:Banyumedia Publissing,

Bungin,Burhan. 2010. Metodologi Penelitian Kualitatif.Jakarta:Rajawali Pers.

Arikunto,Suharsimi. 2002. Prosedur Penelitian Suatu Pendekatan Praktik.Jakarta:Rineke Cipta.

Creswell,John. 2013. Researc Design Pendekatan Kualitatif, Kuantitatif ,Dan Mixed. Yogyakarta:Pustaka Belajar. 